\title{
Transiciones y tránsitos de la comunicación audiovisual
}

\section{Transitions and Transits of Audiovisual Communication}

\section{Transições e trânsitos da comunicaçao audiovisual}

EDUARDO A. RUSSO

earusso@fba.unlp.edu.ar - Editor invitado / Instituto de Producción y Enseñanza del Arte Argentino y Latinoamericano, Facultad de Artes, Universidad Nacional de La Plata, Argentina.

ORCID: https://orcid.org/0000-0003-4662-0961

CÓMOCITAR:Russo,E.A. (2021).Transicionesytránsitos dela comunicación audiovisual. InMediaciones de la Comunicación, 16(1), 25-34. DOI: http://doi.org.10.18861/ ic.2021.16.1.3108

\section{PRÁCTICAS Y DINÁMICAS DE PANTALLA}

El presente número de InMediaciones de la Comunicación aborda el territorio de la comunicación audiovisual desde ángulos y enfoques variados, como corresponde a un objeto multiformey de complejidad creciente. Una evidencia se afirma en las últimas décadas: la sociedad y la cultura contemporáneas dependen cada vez más de pantallas, y aunque la experiencia audiovisual no sea la única actividad vivida ante o a través de ellas, ocupa un espacio y un tiempo cada vez más relevante. No hace falta más que examinar la breve historia de algunas aplicaciones de la sociedad de redes como Instagram, originada para 
un ámbito fundamentalmente fotográfico, pero rápidamente extendida hacia lo audiovisual por sus vivos y sus historias, o el más reciente y sintomático fenómeno de TikTok, para advertir las nuevas formas en curso. Esas experiencias audiovisuales tejen un entramado tan envolvente e intrincado, tan dispuesto a comunicar, expresar, disfrutar, utilizar o hasta padecer, como complejo de inteligir.

Medios audiovisuales, plataformas, aplicaciones de redes sociales, todas coexisten en un estado fluido, con intercambios y modulaciones recíprocas, asumiendo nuevas materialidades y formas. El proceso de remediación, esto es, el modo en que se produce la incorporación yla representación de un medio en otro, detectado ya hace algunas décadas, es decisivo en esta configuración (Bolter \& Grusin, 1999). Por ejemplo, YouTube selanzó en 2005 tomando como emblema el ya obsoleto tubo de rayos catódicos, con la promesa de la posibilidad de emisión por parte de cada usuario. Ofreció un horizonte nuevo bajo una consigna que evocaba a la vieja televisión: broadcast yourself. Pasó pronto de ser, inicialmente, un reservorio global de clips de video de baja resolución, a constituir una plataforma de todo tipo de producciones, cuyas prestaciones se extienden desde lo audiovisual a la música y, al menos por un tiempo, a los videojuegos. Si bien es un caso destacado, YouTube es uno de los tantos sitios que convive con muchas otras plataformas y aplicaciones audiovisuales, imposibles de enumerar aquí, pero que todos reconocemos en nuestro día a día.

¿Cómo hemos llegado a esta situación, configurada por fenómenos tan reconocibles como complejos de desentrañar? Por cierto, aún vemos películas, prendemos los televisores, almacenamos archivos audiovisuales en soporte físico, y paralelamente nos conectamos a plataformas de streaming media y a las redes sociales. Tecnologías, aparatos, soportes, formas y contenidos se suceden y negocian, entre ellos y con nosotros. No obstante, seguimos diciendo "cine”, "televisión", “video", "películas” (aunque ya no haya ninguna película física en juego), "rodaje” (aunque nada ruede en el interior de una cámara), y así podríamos seguir. Lo que permanece son los términos, las identidades y el reconocimiento de cierto tipo de experiencias, más que de los propios medios específicos. Por ejemplo, eso que designamos cine es hoy, ante todo, una experiencia reconocible, un punto de encuentro más que una entidad tecnológicamente definida. Y estas experiencias mutan, se remedian y relocalizan (Casetti, 2015).

Por supuesto que hubo épocas donde lo audiovisual se centraba en experiencias centralizadas, altamente localizables en el tiempo y en el espacio, cuya actividad estaba codificada en términos sociopsicológicos: se trataba de ir al cine. Nótese que el cine era no solamente el nombre de una nueva forma de experiencia audiovisual, sino también el modo de designar allugar físico donde se veían las películas. En ese tiempo pionero, el de la primera mitad del siglo XX, la invención puesta en marcha a fines de la centuria anterior había prendido 
en el tejido social a escala planetaria. El imperio del cine fue indiscutido hasta la culminación de la Segunda Guerra Mundial. El espectáculo cinematográfico modeló, con relaciones estrechas con la prensa escrita, la joven radio y el omnipresente entorno de la música grabada, un intrincado panorama medial que la incorporación de la televisión haría bastante más complejo a partir de los años 50. Se abrió entonces un mundo de dos pantallas coexistentes, aquella enorme que aguardaba en las salas oscuras, y otra más pequeña, que irradiaba sus imágenes desde los televisores hogareños. Ese fue el escenario abierto y preponderante durante la segunda mitad del siglo XX; durante esas décadas las pantallas hogareñas se multiplicaron $y$, con el tiempo, llegaron a ocupar varios espacios en cada casa.

Hacia los años 80, esas dos pantallas ofrecían una vinculación renovada: con las imágenes electrónicas, por entonces analógicas, también aparecieron nuevos elementos para multiplicar las experiencias audiovisuales de manera exponencial. Los sistemas de TV por cable junto a ciertos adminículos como el control remoto, fundamentales para acceder a la mayor oferta de señales, más otros aparatos conectables con los televisores, como las videograbadoras o las primeras consolas de juego, hicieron delo audiovisual un campo de actividades emergentes que modelarían la percepción y la sensibilidad de generaciones. El presunto combate a muerte entre el cine y la televisión, más imaginado por facciones teóricas y especialistas embarcados en estudiar sólo una parte del audiovisual en marcha, identificados algunos con los Film Studies y otros con los Media Studies, no era tal. La verdadera relación entre el cine yla televisión, lejos de ser rivalizante, incluyó tempranas transacciones, negociaciones y repartos jurisdiccionales: el campo de las teleseries, las viejas películas del cine sonoro repetidas durante décadas enteras por la televisión, la neotelevisión por cable y el mercado de los videocasetes, que amplió la recepción cinematográfica más allá de la sala y antes de su llegada a la emisión televisiva, daban claras señales de un sistema cuya consolidación dependía de una realimentación sinérgica. Dos décadas más adelante, al atravesar los últimos años del siglo XX, el ecosistema audiovisual ya había integrado una tercera pantalla, propia del umbral digital: soportes digitales e Internet mediante, la experiencia audiovisual socavó viejas especificidades y se hizo aun más fluida (Marchessault \& Lord, 2008).

El imaginario digital, con su capacidad hibridante y contaminante (su condición viral, tal como lo designará popularmente el término consagrado), se reveló como una fuerza que trastocó y multiplicó el entorno audiovisual, en sentido amplio. Afectó a las formas de producir, de distribuir y de contactarse con lo audiovisual. Se trataba de algo que no era solamente una cuestión de nuevas imágenes, sino que se relacionaba con un nuevo régimen de lo visible y lo audible, mediado en formas cada vez más proliferativas y cambiantes. Las pantallas del presente se han convertido en interfaces de experiencias audiovisuales que se desprenden de su pertenencia a un marco, soporte o aparato 
concreto. Las plataformas audiovisuales no dependen de su instalación en un solo hardware determinado, sino que su arquitectura informática se adapta a un conjunto de configuraciones técnicas, aptas para instalarse en un Smart TV, una computadora, una tableta o un teléfono móvil. A fines del siglo anterior, el artista y teórico Lev Manovich (2005) planteaba que los nuevos medios poseían un lenguaje emergente. Él pensaba no en un lenguaje consolidado, con una gramática prescriptiva, sino que advertía el potencial de un lenguaje poético, propicio a la invención permanente. Pero una década después, indagando lo ocurrido a comienzos del nuevo siglo, Manovich (2013) prefirió desplazar la atención de las definiciones mediales tradicionales hacia una nueva era, donde el software y las aplicaciones ya imponían otras dinámicas y otras reglas de juego. La misma idea de medios audiovisuales es carcomida por una gama de aplicaciones tan cambiantes que, jugando con las metáforas del mundo orgánico, pueden ser consideradas como especies mediales, con un gran potencial evolutivo.

La experiencia actual de la comunicación audiovisual es una amalgama de tradición y transformación, que incluso exige no tomar al inicio del cine como un punto de partida, sino como una encrucijada en una sucesión y entramado de prácticas de pantalla que recoge espectáculos, relatos e imágenes de siglos precedentes. Así lo entendió Anne Friedberg (2009) cuando ligó al sistema de representación renacentista con las pantallas de las computadoras actuales en su libro The Virtual Window: From Alberti to Microsoft. La superficie de un lienzo, la pantalla de cine, los tubos de rayos catódicos, hasta llegar a los displays planos de pequeño formato que utilizamos en nuestras manos, los monumentales que se despliegan en los espacios públicos urbanos o los que instalamos, capacidad de consumo mediante, en nuestras casas. Sin ser protagonista central, el cine, acaso por la extensa historia y las intensidades que comporta la frecuentación de sus producciones, es aún un punto de referencia ineludible y subsiste renovado, más allá de la obsolescencia de la tecnología puesta a punto por los hermanos Lumière y sus competidores de finales del siglo XIX (Albera \& Tortajada, 2010). Pero durante las últimas décadas, el cine ha atravesado procesos multiplicadores y metamórficos que, bajo las características de lo expandido -término utilizado sincrónicamente en América y Europa desde los años sesenta-, le permite persistir más allá de la vigencia del soporte y el aparato fílmico, y no ha dejado de incidir en su remediación a través de otras materialidades de la comunicación (Shaw \& Weibel, 2003; Rees, 2010).

Ya instalado en el siglo XXI, el cine, desafiado por las experiencias audiovisuales de un mundo en el que conviven pantallas de sala, proyecciones hogareñas, visualizaciones portátiles y ubicuas a través de dispositivos móviles y computadoras, reclama la atención no de sus especificidades, sino de los procesos de convergencia medial y de una dinámica de pantallas (Pantenburg, Rohtöhler \& Koch, 2012). Algo similar sucede con ellegado dela vieja 
televisión, al menos como invención tecnológica que tiene la aspiración de transmitir las imágenes producidas con la sincronicidad de la comunicación telefónica. En ese sentido, incluso nuestros actuales intercambios por Zoom, Skype o Meet tienden lazos con las utopías decimonónicas que impulsaron la invención de lo televisivo.

InMediaciones de la Comunicación ha reunido, a través de una convocatoria signada por el tríptico compuesto por las tradiciones, las transformaciones y las proyecciones del territorio audiovisual, un conjunto de artículos, reseñas y entrevistas que buscan seguir pensando algunas de las cuestiones cruciales que atraviesan su contemporaneidad. La revisión de trayectorias históricas desde perspectivas contemporáneas, el examen riguroso de los actuales procesos de transformación medial y la evaluación de las proyecciones de un campo audiovisual de expansión y complejización creciente son los rasgos que caracterizan al conjunto de los textos seleccionados.

\section{CARTOGRAFÍAS, PERSPECTIVAS, PROSPECTIVAS}

Empecemos a dar cuenta de este número de InMediaciones de la Comunicación haciendo referencia a las entrevistas realizadas a dos destacados referentes de la investigación, la docencia y la escritura sobre el cine y el audiovisual latinoamericano, cuya producción se extiende a escala global. Los estudios del brasileño Ismail Xavier se han constituido, desde los años setenta del siglo pasado, en una obra de consulta obligada, no sólo en lo que respecta al estudio del cine de su país, sino también por sus decisivas incursiones en el campo de la historia y la teoría cinematográfica, especialmente sobre los conceptos de modernidad y contemporaneidad (Xavier, 2008, 2013). El investigador paulista es un interlocutor clave para pensar y apreciar el estado del conocimiento sobre el cine y lo audiovisual en la región. De allí que el diálogo mantenido sea un gran aporte para repensar la trayectoria de los estudios sobre el cine, el impacto de la revolución digital y la creación de nuevas perspectivas de trabajo en generaciones recientes. Las ideas de nación y de modernidad en el cine, el ascenso de los estudios comparatistas y los desafíos que comporta en el ámbito audiovisual, junto al surgimiento y la instalación de los nuevos medios, son contemplados por una mirada tan atenta a la visión de conjunto como a la percepción del matiz relevante.

La segunda entrevista, realizada a Jorge La Ferla, teórico, artista y curador argentino cuya actividad, desde hace al menos cuatro décadas, se ha convertido en una referencia ineludible al momento de comprender las transformaciones del expandido territorio audiovisual, ofrece una entrada reflexiva para analizar los pliegues de la tradición fílmica, la electrónica y lo digital. Articulando las propuestas de artistas e investigadores claves para la intelección de las metamorfosis mediales en marcha, que afectan el campo del arte, el diseño y la 
comunicación, La Ferla plantea una agenda urgente ante el vórtice audiovisual del presente: "El futuro del cine digital, como la pospandemia, es hoy". En los planteos realizados, como ocurre en su libro Cine (y) digital (La Ferla, 2010), no solamente se delinea un panorama analítico, sino que también se esboza la propuesta de una política de las imágenes contraria a la absorción totalizadora propuesta por la lógica mercantil-espectacular.

Ambos entrevistados dejan advertir, en sus respuestas, ciertos modos compartidos de comprender algunas tradiciones centrales del cine y lo audiovisual en el siglo XX y las renovaciones teóricas que, desde una perspectiva contemporánea, han permitido analizar los cambios actuales. Además coinciden en la mención imprescindible de algunas ideas del extrañado colega y amigo Arlindo Machado, quien falleció en 2020 y cuya obra fue pionera en el estudio del entorno audiovisual expandido, como lo demuestran sus libros: Pre-Cine y Post Cine (2015), El paisaje mediático. Sobre el desafío de las poéticas tecnológicas (2009a) y El sujeto en la pantalla. La aventura del espectador, del deseo a la acción (2009b). No es azaroso que su mención conecte a dos entrevistados de distinta procedencia, pertenencia y trayectoria en el estudio del cine y la producción audiovisual, dado que en ello es posible advertir un signo más de los intercambios y la necesidad de adopción de perspectivas transversales que Machado fue experto en delinear.

\section{EXPANSIONES Y METAMORFOSIS}

En el comienzo de la sección Artículos, el trabajo de Santiago Marino, titulado "Audiovisual ampliado argentino. Regulación y mercado en el gobierno de Cambiemos" (2015-2019)", nos propone seguir y examinar las paradojas planteadas en torno del desarrollo tecnológico y la estrategia regulatoria llevada adelante por el gobierno del entonces presidente argentino Mauricio Macri. En tal sentido, Marino plantea que bajo la propuesta general de promover la convergencia y multiplicar las opciones audiovisuales, el despliegue de medidas adoptadas en esos cuatro años hizo que avanzara una concentración creciente fundada en el privilegio de decisiones de mercado. El artículo progresa a partir de la proposición conceptual de pensar un espacio audiovisual ampliado, donde el tradicional reparto del campo audiovisual en una sección de medios continuos, fundados en la sincronicidad entre emisión y recepción (como la radio y la televisión), y discontinuos, basados en la diferencia temporal entre publicación y consumo (como el cine y el video), se ven radicalmente cuestionados. Las políticas comunicacionales, las tendencias del mercado y el intento de rediseñar el entorno audiovisual argentino en términos de negocios audiovisuales son los ejes centrales trabajados por Marino en base a una investigación multidimensional sostenida por el procesamiento de abundantes datos cuantitativos. 
La concepción de un espacio audiovisual ampliado también es, desde su mismo título, el punto de partida del artículo escrito por César Mora Moreo, Alessandra Puccini Montoya y Enrique Uribe Jongbloed. En "De los medios a la convergencia. La formación del espacio audiovisual ampliado en Colombia”, la sincronicidad entre los procesos mediales convergentes y la centralidad de las políticas gubernamentales, que entienden a la convergencia fundamentalmente como la ampliación del mercado audiovisual, es examinada bajo una perspectiva histórica y analítica que ensaya un intento de periodización del campo audiovisual colombiano y, al igual que Marino, establece algunas líneas de análisis sobre el proceso de concentración que ha tenido lugar en la producción, la distribución y el consumo.

Por su parte, en "Incertidumbre, disgregación y condición humana en los relatos de la filmografía apocalíptica y posapocalíptica del siglo XXI", Silvina Caleri examina las particularidades de las narrativas en pantalla que despliegan un imaginario catastrófico, no a la manera del apocalipsis tradicional provocado por una fuerza divina, sino aquel que es desatado por la humanidad misma. La autora recorre una amplia variedad de relatos audiovisuales contemporáneos en su común delineamiento de un apocalipsis autoinfligido, y en los que no toda la humanidad sucumbe, aunque aquellos que sobreviven lo hacen en territorios de desolación irresoluble. Como ocurre en la imaginación propia del campo de la ciencia ficción en el que se inscribe gran parte de la filmografía analizada, los interrogantes se redirigen, mediante la presencia de lo fantástico y, también, del tratamiento realista y reflexivo de la devastación humana, hacia cuestiones muy concretas de la existencia que le toca atravesar a sus espectadores y se delinea como rasgo de la contemporaneidad.

En el cuarto artículo, titulado: “Una aproximación al análisis audiovisual y narrativo de la película Roma”, Isaac León Frías elige la estrategia del análisis cinematográfico a la hora de profundizar la mirada sobre la premiada obra de Alfonso Cuarón, al que enriquece con aproximaciones cercanas al neoformalismo y del que extrae una panoplia de sentidos que refieren a los subsistemas estilístico y narrativo del film. Asimismo, La propuesta de León Frías permite acercarnos a la confluencia entrela pantalla cinematográfica yla televisiva, algo que en el caso de Roma se expone a partir de la intervención de la plataforma audiovisual Netflix en la escena del cine de autor contemporáneo: un caso piloto de la expansión de lo cinematográfico a una experiencia audiovisual relocalizada. Expansión que no solamente afecta a sus circunstancias de consumo, sino que comporta un particular despliegue de la primacía del espacio cinematográfico en el relato cinematográfico.

En "El problema político-ontológico de la imagen digital. La herencia del cine ensayo como forma de resistencia subjetiva", Gustado Celedón aborda los aspectos estéticos, políticos y ontológicos de la creación audiovisual contem- 
poránea. Remarca una dimensión clave de la realización audiovisual digital crecientemente hegemónica: su arquitectura fundada en algoritmos que hacen del lenguaje un asunto de programación en sentido amplio. No solamente se trata de hacer operar mediante un software, sino de modelar y conducir sujetos programables. El autor advierte, apelando a una concepción de lenguaje que remite a su acepción más rígida, en tanto sistema de signos prefijados, que en estas circunstancias acecha un proceso de des-subjetivación que sólo puede combatirse por medio de un acto de subversión semiótica. Es decir, desprendiendo a la experiencia audiovisual de su código intrínseco. Celedón toma las experiencias del cine ensayo como factor clave de esa lucha por un sentido abierto, que no es sino un aspecto más del combate por la subjetivación.

El acercamiento ontológico es también escogido como punto de partida por Patricia Bernal Maz en su artículo "El hombre híbrido. El fantasma de la inmortalidad en las narrativas audiovisuales y publicitarias", que toma a un relato documental y a una serie de cortos publicitarios para examinar ciertos espectros que se extienden sobre las pantallas, atravesando géneros y discursos presumiblemente diferentes. La noción de hibridación, frecuentemente acudida en los estudios contemporáneos al referir a medios o discursos, se centra aquí en la constitución del propio sujeto como entidad híbrida. La dimensión del cuerpo y de una percepción corporizada en el espectador tiene en la actualidad una importancia creciente (Casetti, 2015; Gallese \& Guerra, 2019), algo que la autora examina, a través de los casos analizados, en su relación con el paso del tiempo y la mortalidad.

Finalmente, el número se cierra con dos reseñas bibliográficas dedicadas a un par de libros que constituyen una muestra cabal del espectro temático al que se consagra esta publicación de InMediaciones de la Comunicación. En su reseña de Al margen del tiempo. Deseos, ritmos y metáforas en el cine argentino, libro de Julia Kratje publicado en el año 2019, Paz Escobar nos invita a recorrer un innovador estudio en el que confluyen ideas y políticas de género, aproximaciones desde la teoría estética y el análisis cinematográfico a la hora de comprender y reflexionar sobre las modulaciones poéticas del cine argentino actual que ponen en tensión ciertos regímenes de visibilidad androcéntricos. En tal sentido, Kratje entiende que si el cine es un arte del tiempo, cabe entonces explorar las temporalidades propias de los discursos que, oponiéndose a un ordenamiento opresivo-dispuestos porla heteronormatividadylas exigencias productivas del capitalismo-, exponen otros modos de experiencia y, también, de resistencia, tal como se puede derivarse de la aproximación realizada a los films analizados.

La última reseña, escrita por Cecilia Lacruz, se detiene en Transiciones de lo real. Transformaciones políticas, estéticas y tecnológicas en el documental de Argentina, ChileyUruguay, un libro de 2020 editado por la investigadora argentina Paola Margulis. La localización y la aproximación de los distintos artículos 
que componen estelibro, centrado en el documental político argentino, chileno yuruguayo sobrelos procesos de justicia transicional posteriores alas experiencias autoritarias vividas en los países mencionados, ofrece además un capítulo dedicado al problema del archivo y el rescate y la disponibilidad de este tipo de producciones documentales. Asimismo, las dilucidaciones propias de cada uno de los trabajos reunidos dejan entrever un entrelazado donde actúan ciertas conexiones epistémicas: sin rehuir el necesario debate, es posible observar cómo se entrama desde la academia un esfuerzo colectivo en el que convergen perspectivas asociadas al arte, al diseño y la comunicación. Por otra parte, la atención consagrada a las incidencias de los cambios tecnológicos, las estéticas y las poéticas pueden ser considerados, junto a la dimensión política del relato documental, como cuestiones posibles de ser ligadas a la intervención artística y la transformación del mundo, algo con lo que la experiencia audiovisual está íntimamente imbricada.

\section{REFERENCIAS}

Albera, F. \& Tortajada, M.(2010).Cinemabeyond film. Mediaepistemologyin the Modern Era. Amsterdam: Amsterdam University Press.

Bolter, J. D. \& Grusin, R. (1999). Remediation. Understanding new Media. Cambridge: MIT Press.

Casetti, F. (2015). The Lumiere galaxy. 7 Keywords for the cinema to come. New York: Columbia University Press.

Friedberg, A. (2009). The virtual window, from Alberti to Microsoft. Cambridge: MIT Press.

Gallese, V. \& Guerra, M. (2019). The empathic screen. Cinema and neuroscience. Oxford: Oxford University Press.

La Ferla, J. (2010). Cine (y) Digital. Buenos Aires: Manantial.

Machado, A. (2009a). El paisaje mediático. Sobre el desafío de las poéticas tecnológicas. Buenos Aires: Libros del Rojas-EUDEBA.

Machado, A. (2009b). El sujeto en la pantalla. La aventura del espectador, del deseo a la acción. Barcelona: Gedisa.

Machado, A. (2015).Pre-cineypost-cine.En diálogocon losnuevosmedios. Buenos Aires: La Marca Editorial.

Manovich, L. (2005). El lenguaje de los nuevos medios de comunicación. Buenos Aires: Paidós.

Manovich, L. (2013). El software toma el mando. Barcelona: UOC. 
Marchessault, J. \& Lord, S. (2008). Fluid Screens, Expanded Cinema. Toronto: University of Toronto Press.

Pantenburg, V., Rothöhler, S. \& Koch, G. (eds.) (2012). Screen dynamics: Mapping the borders of cinema. Wien: Synema. Gesellschaft für Film und Medien.

Rees, A. L., White, D., Ball, S. \& Curtis, D. (2011). Expanded cinema. Art, performance, film. London: Tate Publishing.

Shaw, J. \& Weibel, P. (eds.) (2003). Future Cinema. The cinematic imaginary after film, Cambridge: MIT Press/ZKM.

Xavier, I. (2008). El discurso cinematográfico. La opacidad y la transparencia. Buenos Aires: Manantial.

Xavier, I. (2013). Cine brasileño contemporáneo. Buenos Aires: Santiago Arcos.

\section{(cc) $\mathbf{B Y}$}

Artículo publicado en acceso abierto bajo la Licencia Creative Commons - Attribution 4.0 International (CC BY 4.0

\section{IDENTIFICACION DEL EDITOR INVITADO}

Eduardo A. Russo. Doctor en Psicología Social, Universidad J. F. Kennedy(Argentina). Director, Doctorado en Artes, Facultad de Artes, Universidad Nacional de La Plata (Argentina). Profesor, Doctorado en Arquitectura y Diseño, Maestría en Diseño Comunicacional y Maestría en Diseño Interactivo, Facultad de Arquitectura, Diseñoy Urbanismo, Universidad de Buenos Aires (Argentina); Doctorado en Diseño, Universidad de Palermo (Argentina); Facultad de Artes, Universidad Nacional de La Plata (Argentina); Escuela Nacional de Experimentación y Realización Cinematográfica (Argentina). Profesor visitante de grado y posgrado en universidades de Chile, Colombia, Brasil, Uruguay, Cuba y México. Sus proyectos actuales como investigador abordan la articulación entre cine, diseño audiovisual, nuevos medios y arte contemporáneo. Autor de los libros: Diccionario de Cine (1998) y El cine clásico: itinerario, variaciones y replanteos de una idea (2008). Compilador de: Interrogaciones sobre Hitchcock (2001); Cine Ojo: un punto de vista en el territorio de lo real (2007), Hacer Cine: Producción Audiovisual en América Latina (2008), The film edge (2010). Compilador, junto a Gerardo Yoel, del libro: Archivos, lecturas, perspectivas. Cine y artes audiovisuales en América Latina (en prensa). Dirige la revista académica Arkadin. Estudios de Cine y Artes Audiovisuales, Universidad Nacional de La Plata (Argentina). 